\title{
A FIXED POINT THEOREM FOR A NONLINEAR TYPE CONTRACTION
}

\author{
S. A. HUSAIN and V. M. SEHGAL \\ Department of Mathematics \\ University of Wyoming \\ Laramie, Wyoming 82071
}

(Received January 31, 1978)

ABSTRACT. A well-known result of Boyd and Wong [1] on nonlinear contractions is extended. Several other known results are obtained as special cases.

INTRODUCTION.

In this paper, we extend a well-known result of Boyd and Wong [1] and obtain as consequences several other known results (see [2], [3], [4], [5]).

Throughout this paper, let $(X, d)$ be a complete metric space, $\mathrm{R}^{+}$the nonnegative reals and $\phi=\phi\left(t_{1}, t_{2}, t_{3}, t_{4}, t_{5}\right):\left(R^{+}\right)^{5} \rightarrow R^{+}$a function which is (a) continuous from right in each coordinate variable (b) nondecreasing in $t_{2}, t_{3}, t_{4}, t_{5}$, and satisfies the inequality (c) $\phi(t, s, s, a s, b s)<\operatorname{Max}\{t, s\}$ if $\operatorname{Max}\{t, s\} \neq 0$ where $\{a, b\} \subseteq\{0,1,2\}$ with $a+b=2$. Note that (c) implies that $\phi(t, t, t, t, t)<t$ for any $t>0$.

\section{MAIN RESULTS.}

The following is the main result of this paper.

THEOREM 1. Let $\mathrm{f}, \mathrm{g}: \mathrm{X} \rightarrow \mathrm{X}$ be two commutative mappings such that

(i) $\quad \mathrm{fX} \subseteq \mathrm{gX}$,

(ii) $\mathrm{g}$ is continuous,

(iii) $d(f x, f y) \leq \phi(d(g x, g y), d(f x, g x), d(f y, g y), d(f x, g y), d(f y, g x))$, for each $x, y \in X$. Then, there exists a unique $u \in X$ with $f u=g u=u$. 
We first prove the following lemma which simplifies the proof of the above theorem.

LEMMA. Under the conditions of Theorem 1, if there exists a $v \varepsilon X$ such that $\mathrm{fv}=\mathrm{gv}$, then there exists a unique $\mathrm{u} \varepsilon \mathrm{X}$ with $\mathrm{fu}=\mathrm{gu}=\mathrm{u}$.

PROOF. We show that for any $w \in X$

$$
f(w)=g(w) \text { implies } f(v)=f(w)
$$

Suppose $t=d(f v, f w)>0$. Then it follows by (iii) that

$$
t \leq \phi(t, 0,0, t, t) \leq \phi(t, t, t, t, t)<t,
$$

a contradiction. Thus $f v=f w$. Now, since $f w=g w$, therefore, $f(f w)=g(f w)$ and consequently by $(2.1)$

$$
f(w)=f(f w)=g(f w) \text {. }
$$

Thus, if we set $u=f(w)$, then $f u=g u=u$. The uniqueness of $u$ now follows from $(2.1)$.

PROOF OF THEOREM 1. Let $x_{0}$ be an arbitrary point in $x$. Construct a sequence $\left\{y_{n}\right\}$ in $x$ as follows. Let $y_{0}=f x_{0}$. By (i) there exists a $x_{1} \varepsilon x$ such that $\mathrm{y}_{0}=\mathrm{gx}_{1}$. Set $\mathrm{y}_{1}=f \mathrm{x}_{1}$. Thus, if $\mathrm{y}_{0}, \mathrm{y}_{1}, \ldots \mathrm{y}_{\mathrm{n}}$ are obtained with $\mathrm{y}_{\mathrm{n}}=f \mathrm{x}_{\mathrm{n}}$, there exists by (i) a $x_{n+1} \varepsilon X$ such that $y_{n}=g x_{n+1}$. Let $y_{n+1}=f x_{n+1}$. Thus, for each $n \in I$ (nonnegative Integers),

$$
\mathrm{y}_{\mathrm{n}}=\mathrm{f} \mathrm{x}_{\mathrm{n}}=\mathrm{gx} \mathrm{x}_{\mathrm{n}+1}
$$

We shall show that $\left\{y_{n}\right\}$ is a Cauchy sequence in $x$. For this, let for each $n \in I, d_{n}=d\left(y_{n}, y_{n+1}\right)$. Then by (i) and (b),

$$
d_{n+1}=d\left(f x_{n+1}, f x_{n+2}\right) \leq \phi\left(d_{n}, d_{n}, d_{n+1}, 0, d_{n}+d_{n+1}\right) .
$$

Now, if for some $n \in I, d_{n+1}>d_{n}$, then by (b) and (c)

$$
d_{n+1} \leq \phi\left(d_{n}, d_{n+1}, d_{n+1}, 0,2 d_{n+1}\right)<d_{n+1},
$$


a contradiction. Thus for each $n \in I, d_{n+1} \leq d_{n}$, that is $\left\{d_{n}\right\}$ is a nonincreasing sequence of nonnegative reals and consequently there exists a $d \varepsilon R^{+}$such that $\left\{d_{n}\right\} \rightarrow d$. Clearly $d=0$, for otherwise by (2.3) and (c),

$$
d \leq \phi(d, d, d, 0,2 d)<d,
$$

a contradiction. Thus,

$$
d_{n} \rightarrow 0
$$

Suppose, now that $\left\{\mathrm{y}_{\mathrm{n}}\right\}$ is not a Cauchy sequence. Then there exists a $E>0$ such that for each $k \varepsilon I$, there exist integers $n(k), m(k)$ with $k \leq n(k)<m(k)$ satisying

$$
E_{k}=d\left(y_{n(k)}, y_{m(k)}\right)>E \text {. }
$$

Let $m(k)$ be the least integer greater than $n(k)$ such $(2.4)$ holds. This implies that for each $k \in I, d\left(y_{n(k)}, y_{m(k)-1}\right) \leq E$. Consequently, for each $k \in I$,

$$
E<E_{k} \leq d\left(y_{n(k)}, Y_{m(k)-1}\right)+d\left(y_{m(k)-1}, Y_{m(k)}\right) \leq E+d_{k} \cdot
$$

Hence, it follows by (2.4) that as $k \rightarrow \infty, E_{k} \rightarrow E$.

However, for each $k \in I$,

$$
\begin{aligned}
E_{k} & \leq d_{n(k)}+d\left(f x_{n(k)+1} f_{m(k)+1}\right)+d_{m(k)}, \\
& \leq 2 d_{k}+\phi\left(E_{k}, d_{k}, d_{k}, E_{k}+d_{k}, E_{k}+d_{k}\right),
\end{aligned}
$$

Therefore, as $\mathrm{k} \rightarrow \infty$,

$$
\mathrm{E} \leq \phi(\mathrm{E}, 0,0, \mathrm{E}, \mathrm{E})<\mathrm{E},
$$

contradicting the existence of $E>0$. Thus, $\left\{y_{n}\right\}$ is a Cauchy sequence in $X$. Consequently, there is a $v \in X$ such that $\left\{y_{n}\right\} \rightarrow v$, that is

$$
f x_{n}=g x_{n+1} \rightarrow v \text {. }
$$

We show that for this $v$,

$$
\alpha=d(f v, g v)=0 \text {. }
$$


Suppose $\alpha>0$. Now by (ii) and (2.6) we have,

$$
f g x_{n}=g f x_{n} \rightarrow g v \text { and } g^{2} x_{n} \rightarrow g v
$$

Also, it follows by (b) and (iii) that,

$$
d\left(f\left(g x_{n}\right), f v\right) \leq \phi\left(d\left(g^{2} x_{n}, g v\right), d\left(f g x_{n}, g^{2} x_{n}\right), \alpha, d\left(f g x_{n}, g v\right), \alpha+d\left(g v, g^{2} x_{n}\right)\right) .
$$

Therefore, as $\mathrm{n} \rightarrow \infty$, the above inequality yields that

$$
\alpha=\mathrm{d}(\mathrm{gv}, \mathrm{fv}) \leq \phi(0,0, \alpha, 0, \alpha)<\alpha,
$$

a contradiction. Thus $\mathrm{fv}=\mathrm{gv}$ and hence by the above lemma, there is a unique $u \in X$ satisfying $\mathrm{fu}=\mathrm{gu}=\mathrm{u}$.

In the special case when $g$ is taken to be the identity map of $x$ in Theorem 1 , we have

COROLLARY 1. Let $\mathrm{f}: \mathrm{X} \rightarrow \mathrm{X}$ satisfy either of the following conditions: for all $\mathrm{x}, \mathrm{y} \in \mathrm{X}$,

(A). $d(f x, f y) \leq \phi(d(x, y), d(x, f x), d(y, f y), d(x, f y), d(y, f x))$.

(B). $d(f x, f y) \leq \alpha(d(x, f x)+d(y, f y))+\beta(d(x, f y)+d(y, f x))+\Psi(d(x, y))$

where $\alpha \geq 0, \beta \geq 0$ and $\Psi: \mathrm{R}^{+} \rightarrow \mathrm{R}^{+}$is a right continuous function satisfying $\Psi(t)<(1-2 \alpha-2 \beta) t$ if $t>0$. Then $f$ has a unique fixed point in $x$.

PROOF. The conclusion is an obvious consequence of Theorem 1 if (A) holds. In case of condition (B), let $\phi:\left(\mathrm{R}^{+}\right)^{5} \rightarrow \mathrm{R}^{+}$be defined by

$$
\phi\left(t_{1}, t_{2}, t_{3}, t_{4}, t_{5}\right)=\psi\left(t_{1}\right)+\alpha\left(t_{2}+t_{3}\right)+\beta\left(t_{4}+t_{5}\right) .
$$

then $\phi$ satisfies conditions (a), (b) and (c). Thus the conclusion again follows by Theorem 1 .

It may be remarked that if $\alpha=\beta=0$ in (B) then Corollary 1 yields a wellknown result of Boyd and Wong [1]. If $\psi(t)=\alpha t$, then Corollary 1 yields certain results of Hardy and Rogers [2], Kannan [3], Reich [4], Sehgal [5]. All these results are special cases of Theorem 1 . 


\section{REFERENCES}

1. Boyd, D. W. and S. W. Wong. On Nonlinear Contractions, Proc. Amer. Math Soc. 20 (1969) 458-464.

2. Hardy, G. E. and T. D. Rogers. A Generalization of a Fixed Point Theorem of Reich, Canad. Math. Bull. 16 (2) (1973) 201-206.

3. Kannan, R. Some Remarks on Fixed Points, Bul1. Cal. Math. Soc. 60 (1968) 71-76.

4. Reich, S. Kannan's Fixed Point Theorems, Bu11. U.M.I. 4 (1971) 1-11.

5. Sehgal, V. M. Some Fixed and Common Fixed Point Theorems in Metric Spaces, Canad. Math. Bull. 16 (1974) 257-259.

KEY WORDS AND PHRASES. Nonlinear type contraction, Fixed point theorems.

AMS (MOS) SUBJECT CLASSIFICATIONS (1970). 47 H10. 


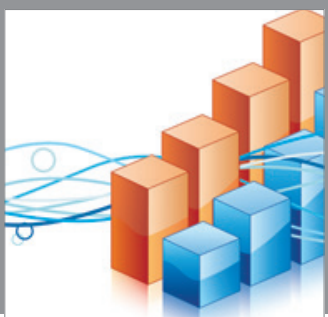

Advances in

Operations Research

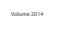

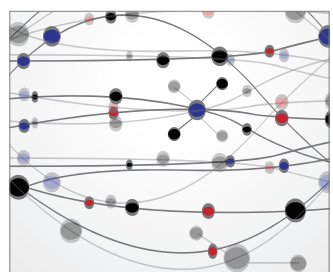

\section{The Scientific} World Journal
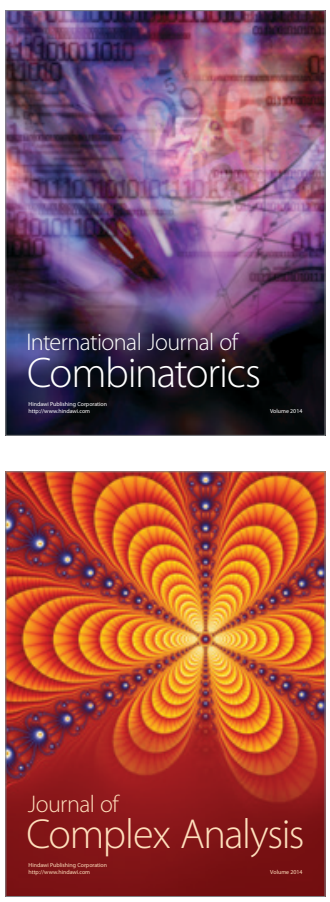

International Journal of

Mathematics and

Mathematical

Sciences
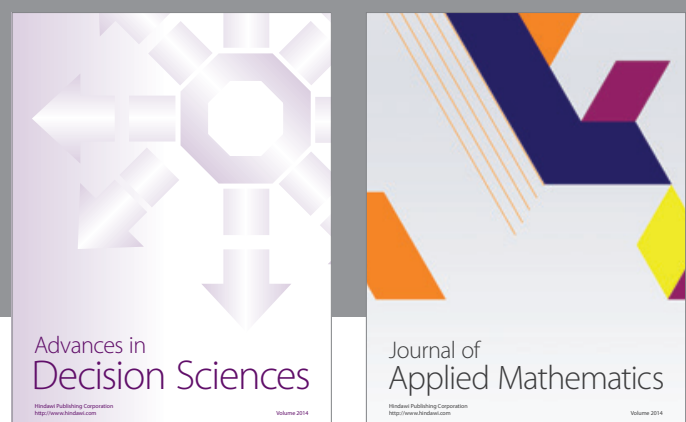

Journal of

Applied Mathematics
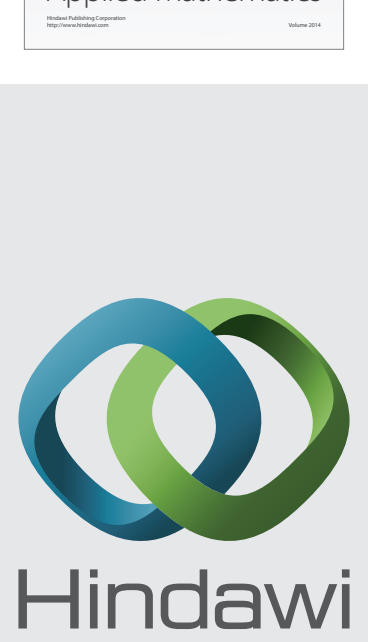

Submit your manuscripts at http://www.hindawi.com
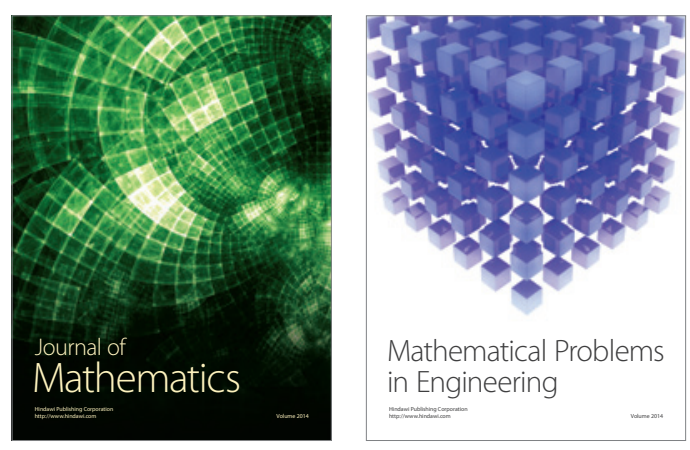

Mathematical Problems in Engineering
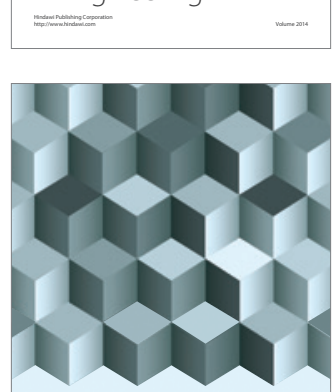

Journal of

Function Spaces
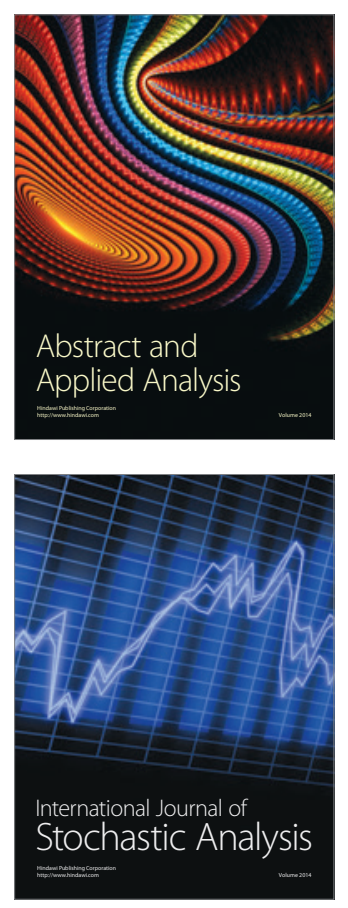

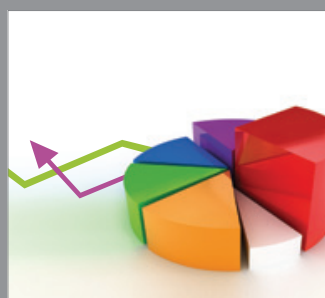

ournal of

Probability and Statistics

Promensencen
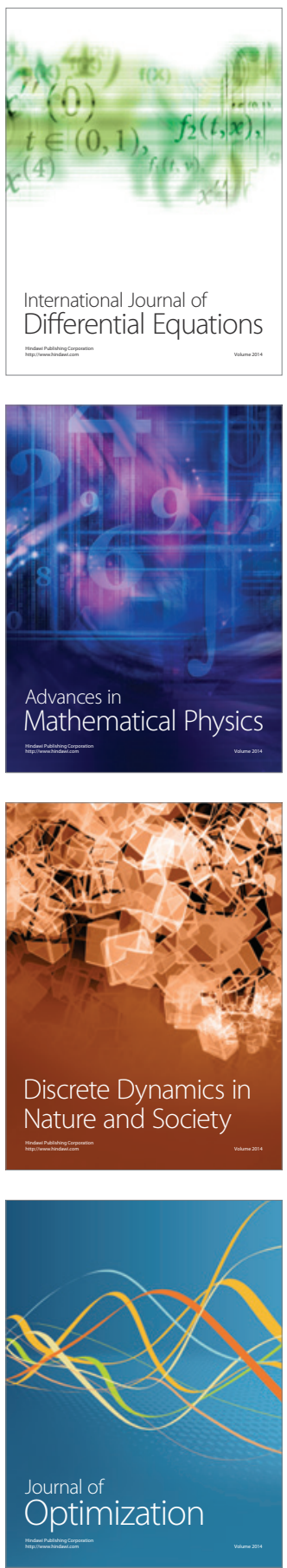